\title{
Inclusão de colesterol e seus efeitos no potencial de membrana mitocondrial de espermatozoides criopreservados de jumentos da raça Pêga
}

Flávia Vieira de Freitas ${ }^{[]^{*}}$, Maria Eduarda Borges Figueira, Cristian da Silva Teixeira ${ }^{[b]}$, Thiago Augusto Teles de Souza ${ }^{[b]}$, Carlos Mattos Teixeira Soares ${ }^{[b]}$, Maria Gazzinelli Neves ${ }^{[b]}$, Bruna Waddington de Freitas ${ }^{[b]}$, Larissa Marques de Oliveira ${ }^{[b]}$, Marina da Silva Passarelli[i], Mariana Andrade Torres ${ }^{[a]}$, Simone Maria Massami Kitamura Martins ${ }^{\left[{ }^{[a]}\right.}$, André Furugen Cesar de Andrade ${ }^{\left[{ }^{[a]}\right.}$, Giovanni Ribeiro de Carvalho[b]

\footnotetext{
[a] Universidade de São Paulo (USP), Pirassununga, SP, Brasil

[b] Universidade Federal de Viçosa (UFV), Viçosa, MG, Brasil
}

*Autor correspondente

e-mail: flavia.vet10@gmail.com

\section{Resumo}

A criopreservação pode afetar o espermatozoide de várias maneiras, e dentre estas é possível salientar o comprometimento da função das mitocôndrias. A mitocôndria espermática é uma das organelas mais importantes do espermatozoide, pois é através da adequada funcionalidade desta estrutura que advém a principal fonte energética para a movimentação do flagelo, estrutura responsável pela chegada do espermatozoide ao sítio de fertilização do ovócito. Com o advento de novos diluidores e aditivos foi possível minimizar os danos causados pela criopreservação. Neste sentido, a adição de colesterol ao sêmen de jumentos, em concentrações adequadas, pode preservar as características físicas e metabólicas do gameta masculino. Além disso, com o desenvolvimento de sondas fluorescentes mais sensíveis e específicas, foi possível detectar os reais danos causados pela preservação pelo frio. Este estudo objetivou avaliar os efeitos da inclusão de colesterol ao sêmen de jumentos da raça Pêga na preservação do potencial de membrana mitocondrial $(\Delta \Psi \mathrm{m})$. Para isto, foram utilizadas cinco colheitas de sêmen de cinco jumentos da raça Pêga, com idade entre 3 e 10 anos e peso médio de $300 \mathrm{Kg}$. Após as avaliações do sêmen in natura, este foi dividido em duas alíquotas, destinadas grupo controle (GC) e grupo tratado (GT). O sêmen do GC foi diluído em meio à base de leite em pó (Botu-Sêmen ${ }^{\circledR}$ - Botupharma Botucatu, SP, Brasil) em proporção 1:1, centrifugado a 600 g durante 15 minutos, ressuspendido com meio à base de gema de ovo (Botu-Crio ${ }^{\circledR}$ - Botupharma Botucatu, SP, Brasil) para obtenção de concentração de 200 x 106 espermatozoides/mL, envasado em palhetas francesas de 0,5 $\mathrm{mL}$, refrigerado a ${ }^{\circ} \mathrm{C}$ durante 20 minutos, mantido a $4 \mathrm{~cm}$ do vapor de nitrogênio durante 15 minutos e mergulhado em nitrogênio líquido para congelamento do sêmen. 0 sêmen do GT foi previamente incubado com 1,5 mg de ciclodextrina (C4555 - Sigma-Aldrich, St. Louis, Missouri, EUA), carregada com colesterol (C3045 - Sigma-Aldrich, St. Louis, Missouri, EUA) a cada 120 x 106 espermatozoides/mL durante 15 minutos 
à temperatura ambiente e protegido da luz. Após este tempo, o sêmen do GT foi diluído em meio à base de leite em pó (Botu-Sêmen ${ }^{\circledR}$ - Botupharma Botucatu, SP, Brasil) em proporção 1:1 e procedeu-se com as mesmas etapas de criopreservação do GC. Para avaliação do potencial de membrana mitocondrial, as palhetas foram descongeladas em banho-maria a 37ํㅡ C durante 30 segundos, e seu conteúdo incubado com $1 \mu \mathrm{L}$ de cada uma das sondas fluorescentes, sendo elas Syto-59 (Molecular Probes Inc., Eugene, Oregon, EUA), Iodeto de Propídio (Sigma-Aldrich, St. Louis, Missouri, EUA) e JC-1 (Molecular Probes Inc., Eugene, Oregon, EUA). As análises foram realizadas em aparelho de citometria de fluxo modelo BDAccuri C6 (Beckton-Dickeson, San Jose, USA). Os dados foram analisados pelo programa SAS (SAS Institute Inc., 2010). Houve efeito $(\mathrm{P}<0,05)$ da inclusão de colesterol na manutenção de alto $\Delta \Psi \mathrm{m}$, com maiores valores de $\Delta \Psi \mathrm{m}$ para o GT $(15,49 \pm 2,47)$ em relação ao GC $(6,30 \pm 1,07)$. Diante dos resultados expostos, é possível concluir que a adição do colesterol ao sêmen de jumentos da raça Pêga, na concentração utilizada, foi capaz de perservar um alto $\Delta \Psi \mathrm{m}$, sendo recomendado para tal finalidade.

Palavras-chave: Colesterol. Ciclodextrina. Mitocondria. 